\title{
Immune complexes and rheumatoid factors in canine arthritides
}

\author{
S D CARTER, S C BELL, A S M BARI, AND D BENNETT \\ From the Arthritis Research Group, Departments of Veterinary Pathology and of Veterinary Clinical Science \\ University of Liverpool, Liverpool
}

SUMmaRY Thirty two domestic dogs with naturally occurring polyarthritis were investigated tộ determine the contribution of autoimmunity in the pathological mechanisms. Comparisons wer $\dot{\infty}_{\infty}$ made with canine infective arthritis (12 dogs), osteoarthritis (32), and osteoarthritis secondary to rupture of the cranial cruciate ligament (19). Rheumatoid factors, immune complexes, ande complement fixation ( $\mathrm{C} 1 \mathrm{q}$ binding) were measured in sera and synovial fluids. Compared witlp normal dogs (32), dogs with rheumatoid arthritis (RA) had increased serum and synovial fluic immune complexes and rheumatoid factors. Increases were generally also seen in dogs with other arthropathies, however. Rheumatoid factors were higher in sera than in synovial fluids $\$$ Rheumatoid factors correlated with immune complex levels and complexed rheumatoid factoo only in the group of dogs with RA. Both rheumatoid factors and immune complexes mays contribute to the pathogenesis of canine RA but are considered to arise as a result of non-specific inflammatory mechanisms in the non-rheumatoid groups.

It has been suggested that a class of naturally occurring canine inflammatory joint disease is similar in many respects to human rheumatoid arthritis (RA). ${ }^{1-6}$ Criteria have been defined for the diagnosis of canine RA and essentially they are as propounded by the American Rheumatism Association for use in man. Similarities between human and canine RA include the age of onset (relative to life span), the symmetrical polyarticular presentation, stiffness after rest, and the involvement of mainly peripheral joints, which show swelling and pain. The course of canine RA is progressive and may lead to severe joint destruction and deformities. Radiological findings are variable, but soft tissue swelling is always present and there is usually rarefaction and erosion of bone in one or more joints. Histopathological features include synovial membrane proliferation with villous hypertrophy and lymphocytic infiltration of the supporting layer, including aggregates of plasma cells. Gradually the articular surface becomes covered with destructive pannus. ${ }^{4}$ Large numbers of polymorphonuclear neutrophils are invariably seen in the synovial fluid. ${ }^{3}$

Accepted for publication 3 March 1989.

Correspondence to Dr S D Carter, Department of Veterinary Pathology, University of Liverpool, PO Box 147, Liverpool L69 3BX.
Antiglobulins (rheumatoid factors) and immune complexes are frequently raised in the sera anfक synovial fluids in man and have been implicated in: the pathological mechanisms of the disease. ${ }^{7}$ There have only been limited studies in the $\operatorname{dog}_{\overrightarrow{0}}$ rheumatoid factors were detected in the sera of some affected dogs. ${ }^{9} 10$ Immune complexes have been found in the sera in canine RA, but only six cases were tested and only three showed an increase. ${ }^{11}$ To date there has been no compres hensive description of immune complexes o. rheumatoid factors in dogs with RA or comparisons with other canine arthritides.

\section{Materials and methods}

A NIMALS

All the dogs had been referred for a second opinion to the Small Animal Hospital by veterinary generaP practitioners. Dogs with a wide spectrum of arthritis diseases were included in the study. Dogs witk inflammatory joint disease included those witw bacterial infective arthritis ${ }^{12}$ and the immune base arthropathies. ${ }^{13}$ The latter were classified as canines rheumatoid arthritis, having satisfied the Americat Rheumatism Association criteria used in man. Thiso group included dogs with erosive and non-erosive disease. $^{34}$ Dogs with degenerative joint diseas 
were mostly those with secondary osteoarthritis resulting from osteochondrosis, ${ }^{14} 15$ joint dysplasia and instability, or from stretching and tearing of the cranial cruciate ligament. ${ }^{16}$ The last group was identified as a separate group as they formed a substantial proportion of the total cases of secondary osteoarthritis and the pathogenesis of this disease may involve immunological mechanisms. ${ }^{17}$ All the other dogs with degenerative joint disease were grouped together. In addition, a normal population of dogs was sampled; these were dogs which were presented to the hospital for reasons other than locomotory disease and which were free of articular disease, as assessed clinically, radiographically, and by synovial fluid analysis. Also, beagles from a breeding colony were used as a source of serum samples and normal synovial fluids.

SERUM SAMPLES AND SYNOVIAL FLUIDS Serum samples were obtained from venous blood. Synovial fluid was aspirated under aseptic conditions from a number of joints. Total and differential white cell counts were performed. Cells were removed from synovial fluid by centrifugation $(1000 \mathrm{~g})$ and the supernatant stored in aliquots at $-23^{\circ} \mathrm{C}$.

\section{IgM RHEUMATOID FACTOR}

RA D I O I M M U NOASSA Y

Mouse monoclonal antibody to human IgM (Oxoid, clone AF6) was used as the developing probe for canine IgM rheumatoid factor. This has previously been shown to bind canine IgM ( $\mu$ chain) by enzyme linked immunosorbent assay (ELISA) and Western blotting (Carter, Bell, Bennett, unpublished data). The IgG fraction was prepared by $40 \%$ ammonium sulphate precipitation of the ascites and labelled with ${ }^{125}$ I by the iodogen method. ${ }^{18}$

Canine IgG was purified from canine sera by $40 \%$ ammonium sulphate precipitation, diethylaminoethyl ion exchange chromatography, and gel filtration in ACA-34 (LKB). ${ }^{19}$ Purity was shown by acetate electrophoresis and polyacrylamide gel electrophoresis $^{20}$ in which only $\gamma$ chains and light chains were detected. Polyvinyl chloride microtitre plates (Linbro) were incubated with monomeric IgG at $10 \mu \mathrm{g} / \mathrm{ml}$ in phosphate buffered saline (PBS) at $37^{\circ} \mathrm{C}$ for one hour and $4^{\circ} \mathrm{C}$ overnight. Unbound material was decanted and the plates incubated with $0.5 \%$ bovine serum albumin at $37^{\circ} \mathrm{C}$ for two hours. The plates were washed with PBS, dried, and stored in a desiccator at $4^{\circ} \mathrm{C}$ until use. Canine sera and synovial fluids $(1 / 1000)$ and immune complex preparations (1/50) were diluted in PBS/ $0.5 \%$ bovine serum albumin $+0.05 \%$ Tween 20 and incubated in the wells in duplicate at $37^{\circ} \mathrm{C}$ for one hour and $4^{\circ} \mathrm{C}$ for one hour, washed with PBS/Tween, and then IgM rheumatoid factor detected with ${ }^{125} \mathrm{I}$ anti- $\mu$ at 20 $\mathrm{ng} / \mathrm{ml}\left(37^{\circ} \mathrm{C}\right.$ for one hour and $4^{\circ} \mathrm{C}$ for one hour). The plates were washed with PBS/Tween, then dried, and the individual wells counted for ${ }^{125} \mathrm{I}$ in a gamma detector (LKB). The results were expressed as the percentage uptake of ${ }^{125} I$ anti- $\mu$ by the wells.

\section{IMMUNE COMPLEXES}

Immune complexes were precipitated from sera and synovial fluids with $2 \cdot 5 \%$ polyethylene glycol 6000 (BDH) at $4^{\circ} \mathrm{C}$ for 90 minutes. ${ }^{21}$ Each precipitate was washed twice with cold $2.5 \%$ polyethylene glycol, resuspended in PBS, and the protein determined by the absorbance at $280 \mathrm{~nm}$ in an LKB spectrophotometer.

The immunoglobulin content of the complexes was determined by radial immunodiffusion. Rabbits were immunised with $\operatorname{dog}$ IgG at $1 \mathrm{mg} / \mathrm{ml}$ in Freund's adjuvant (complete and incomplete) and hyperimmune sera used in 1\% agarose gels (in PBS) for radial immunodiffusion. ${ }^{22}$ Five microlitre samples were added to wells and incubated at $37^{\circ} \mathrm{C}$ for 24 hours. Precipitin rings were measured with a vernier micrometer. Purified dog IgG was used to prepare a standard curve. Although the rabbit antisera had some reaction with light chains (by ELISA), the major reaction was to IgG and there was no precipitation with either purified $\operatorname{dog} \operatorname{IgA}$ or IgM.

\section{C1q BIN DING ASSAY}

Human C1q (Sigma) was coated onto micro-ELISA plates (Flow Ltd) at $10 \mu \mathrm{g} / \mathrm{ml}$ in PBS. Serum samples and synovial fluids, diluted $1 / 100$ in $\mathrm{PBS} / \mathrm{Tween}$ $(0.05 \%)$, were added to the plates. After incubation at $37^{\circ} \mathrm{C}$ for one hour the plates were washed with PBS/Tween and bound immunoglobulins detected with rabbit antidog IgG (1/1000 in PBS/Tween). Alkaline phosphatase conjugated goat antirabbit IgG was used for secondary antibody measurement, followed by the substrate ( $p$-nitrophenyl phosphate). Colour reaction was measured at $405 \mathrm{~nm}$ in a Titertek ELISA reader.

Data were analysed by Student's $t$ test (paired and unpaired) and linear regression analysis.

\section{Results}

IgM RHEUMATOID FACTOR IN SERA

AND SYNOVIAL FLUIDS

Figure 1 shows the results of the IgM rheumatoid factor assays. In both sera and synovial fluids dogs without joint disease had low levels of rheumatoid factor compared with the groups with arthropathy. Many of the dogs with rheumatoid disease had raised serum rheumatoid factor-that is, more than 
two standard deviations above the mean of the normal dogs (31/32). Synovial fluid rheumatoid factor was lower than serum rheumatoid factor in all groups, particularly in normal dogs, in which the rheumatoid factor was usually zero. The rheumatoid factor levels were generally much higher in synovial fluids in the rheumatoid-like group than in the synovial fluids from the control group $(66 / 68 \geqslant 2 S D$ of the mean). Similarly, increased levels were detected in sera and synovial fluids in dogs with infective arthritis, osteoarthritis, and cruciate disease. Table 1 shows the statistical analyses. Comparisons of the data when rheumatoid factor measurements were available for synovial fluids and sera from the same dog showed lower levels of rheumatoid factor activity in the synovial fluids.

Linear regression analysis (Table 1) showed that there was no correlation between serum and synovial fluid rheumatoid factor in the control group, presumably because the levels were low in both. Significant correlations were seen, however, in dogs with infective arthritis, osteoarthritis and, particularly, in dogs with cruciate rupture or RA.

IMMUNE COMPLEXES IN SERA AND

SYNOVIAL FLUIDS

Measurements of complexed protein did not show increased levels in the serum samples of any of the patient groups (data not shown). In a comparison

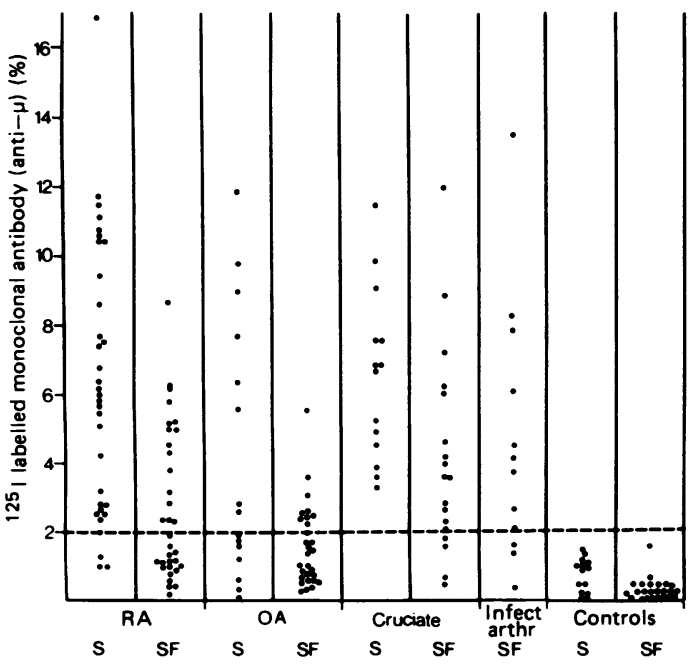

Fig. 1 IgM rheumatoid factor in sera and synovial fluids from dogs with rheumatoid arthritis $(R A)$, osteoarthritis $(O A)$, osteoarthritis secondary to cruciate rupture (cruciate), infective arthritis, and normal dogs (controls). Results are percentage of ${ }^{125}$ I monoclonal anti-IgM bound to the microplate. $S=$ serum; $S F=$ synovial fluid. Each point represents one dog.
Table 1 IgM rheumatoid factor in canine arthritides; statistical analyses comparing data from patient groups with those from normal dogs (Student's $t$ test) and correlating sera and synovial fluid levels in same dogen (linear regression analysis). Values are mean (SD)

\begin{tabular}{|c|c|c|c|}
\hline Group & Serum $R F^{*}$ & $\begin{array}{l}\text { Synovial } \\
\text { fluid } \\
R F\end{array}$ & $\begin{array}{l}\text { Sera } R F \\
v S F^{*} R F \\
(r)\end{array}$ \\
\hline \multicolumn{3}{|l|}{ Rheumatoid } & 0.52 \\
\hline $\mathrm{n}$ & 32 & & 52 \\
\hline$\underset{\mathbf{n}}{\text { Osteoarthritis }}$ & $\begin{array}{l}16 \cdot 23(1 \cdot 50) \\
28\end{array}$ & $\begin{array}{l}7 \cdot 85(7.63) \\
34\end{array}$ & $\begin{array}{l}0 \cdot 43 \\
30\end{array}$ \\
\hline Cruciate $^{*}$ & $14 \cdot 27(1.78)$ & $6.30(0.85)$ & $0 \cdot 77$ \\
\hline $\mathbf{n}$ & 19 & & 23 \\
\hline Infective arthritis & $16.03(1.81)$ & $8.07(1.62)$ & $0 \cdot 63$ \\
\hline $\mathrm{n}$ & 12 & 15 & 12 \\
\hline Control & $3.42(0.42)$ & $0.43(0.05)$ & NS \\
\hline $\mathbf{n}$ & 32 & 58 & 57 \\
\hline
\end{tabular}

${ }^{*} \mathrm{RF}=$ rheumatoid factor; SF=synovial fluid; Cruciate $=0$ steoarthritis secondary to cruciate rupture.

with normal dogs, however, dogs with arthritiç币 changes had statistically increased levels of synoviaß fluid complexes, as measured by protein content $\stackrel{\Phi}{\Phi}$ The increases were seen in all four groups (Table 8 ) $\overrightarrow{.}$ Statistically, there was no difference between 1 ie levels in the different patient groups tested. Measuget ment of the immunoglobulin content of the synovat fluid precipitates paralleled the total protein measurement, and a correlation was found in normal dogs and all of the four patient groupso $(r \geqslant 0.874 ; p<0.01-0.001)$. Complexed immunon globulin was found in both the sera and synovia 5 fluids in normal dogs, and increased amounts were

Table 2 Synovial fluid immune complexes in canine arthropathies; protein measurements (mean (SD)) in $2.5 \%$ polyethylene glycol (PEG) precipitates (Student's test) and correlation of total IgM rheumatoid factor (RF) with precipitated complexes and with IgM RF in PEG precipitates

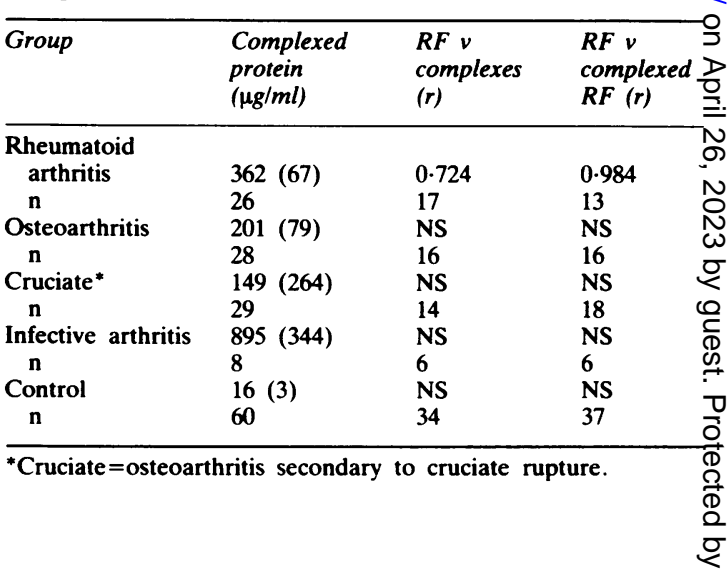


measured in most of the dogs in the patient groups (Fig. 2). The high concentrations recorded in the control dogs were often more than the total protein, as calculated by absorbance at $280 \mathrm{~nm}$, but this is at best a crude estimate. The only group with a significant increase were the dogs with RA, which showed an increase in both sera and synovial fluids $(\mathrm{p}<0 \cdot 05-0 \cdot 001)$.

\section{C1q BIN DING MATERIAL}

The solid phase C1q binding assay showed increased complement fixing complexes in the serum samples of some dogs in all the arthritides groups (Fig. 3). In comparison with the control group, the increases were significant in all the disease groups: rheumatoid arthritis $\mathrm{p}<0.01$, osteoarthritis $\mathrm{p}<0.001$, cruciate rupture $\mathrm{p}<0 \cdot 01$, infective arthritis $\mathrm{p}<0 \cdot 001$.

IgM RHEUMATOID FACTOR IN SYNOVIAL

FLUID IMMUNE COMPLEXES

High levels of rheumatoid factor were found in the

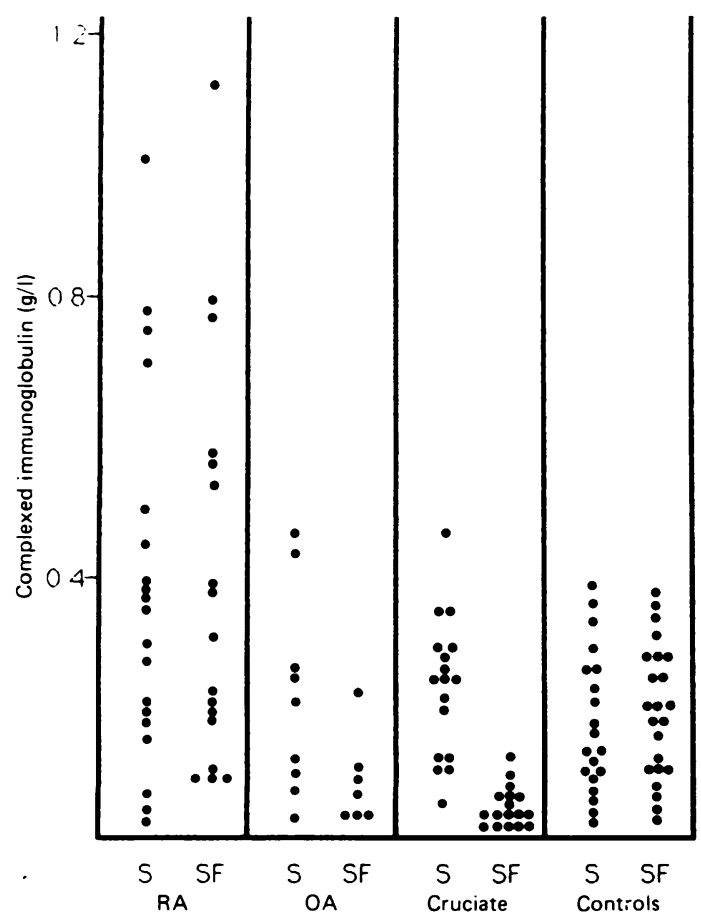

Fig. 2 Complexed immunoglobulins in polyethylene glycol precipitates from sera and synovial fluids in canine arthritides: rheumatoid arthritis $(R A)$; osteoarthritis $(O A)$; osteoarthritis secondary to cruciate rupture (cruciate); and normal dogs (controls). $S=$ serum; $S F=$ synovial fluid. Each point represents one dog.

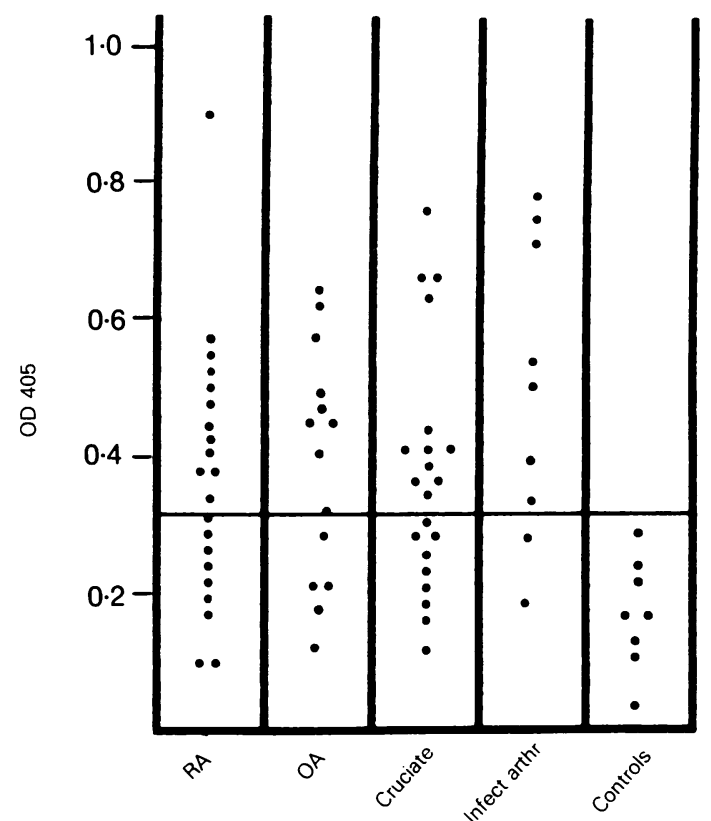

Fig. 3 Cla binding assay in dog sera. Enzyme linked immunosorbent assay (ELISA) data for each dog sample. $R A=$ rheumatoid arthritis; $O A=$ osteoarthritis; cruciate $=$ osteoarthritis secondary to cruciate rupture.

synovial fluid immune complexes from some dogs with joint disease. Linear regression analysis of the data showed correlation of complexed rheumatoid factor with total synovial fluid rheumatoid factor only in those dogs with rheumatoid arthritis (Table $2)$; this correlation was highly significant $(p<0 \cdot 001)$.

RHEUMATOID FACTOR CORRELATION

WITH AGE AND BREED

Dogs of known ages were assayed, but linear regression analysis showed no correlation of rheumatoid factor with age in the rheumatoid group (22 dogs), the osteoarthritis group (33 dogs), or the cruciate group (21 dogs). No correlation was seen when rheumatoid factor presence or levels were compared with the breed of dog; no breed was overrepresented in the positive results or in those with high levels of rheumatoid factor. In all the groups the sexes were represented equally, though the group numbers are not really large enough for adequate statistical analysis. In previous work we have not seen an imbalance of the canine arthritides in the sexes. ${ }^{34}$ 


\section{Discussion}

This study showed that dogs suffering from various arthritides have, in common with man, a number of autoimmunological features which may be important in disease pathogenesis. The finding of rheumatoid factors in canine RA sera is not a new one, though previous studies have only used agglutination methods. ${ }^{9}{ }^{10}$ Synovial fluid rheumatoid factor levels have not been extensively studied; the one available report describes results from only 12 dogs. ${ }^{17}$ Some workers have measured serum immune complexes previously in dogs with connective tissue disorders by using a heterologous system of binding to human C1q, but only in those with cruciate disease. ${ }^{11}$ No reports have been found of analyses of immune complexes from dog synovial fluids.

Normal dogs had lower levels of rheumatoid factor than dogs with joint diseases. As in man, however, the use of a rheumatoid factor assay in the dog does not appear to be able, alone, to distinguish rheumatoid arthritis from other joint diseases; increased amounts of rheumatoid factor were also found in some dogs with osteoarthritis (including those with cruciate disease) and infective arthritis. In contrast with man, very high levels of rheumatoid factor were not found in any of the dogs with RA, ${ }^{23}$ a finding previously reported in the canine disease. ${ }^{9} 10$ Assessment of clinical disease activity in the dog is difficult and only generally possible by radiography. ${ }^{2}$ Both erosive and non-erosive forms of canine RA had raised rheumatoid factor and immune complexes; indeed there were no apparent differences between the two groups in any of the laboratory measurements, suggesting that the same pathological mechanisms are at work in both. Probably, they are different presentations (or degree of progression) of the same disease. The radioimmunoassay used in this study is analogous to the assay previously developed for use in man; indeed it uses the same monoclonal antibody to human IgM. ${ }^{25}$ The use of a Rose-Waaler assay or a latex agglutination system in dogs has been described and shown to be relatively insensitive ${ }^{10}$ although we have found that the sera with the highest titre against dog or rabbit IgG coated sheep red blood cells did have the highest results in the radioimmunoassay. The cleaner system of the radioimmunoassay removes the problems of other factors which influence sheep red cell agglutination and produces more quantifiable results.

The finding of increased rheumatoid factors in both erosive and non-erosive RA, infective arthritis, and osteoarthritis might suggest that rheumatoid factors are a non-specific effect (or mediator) of joint inflammation or that all the arthritides in the dog are immune mediated. It was clear, however that the levels of synovial fluid rheumatoid factors and the levels of rheumatoid factors in synovial fluid immune complexes only correlated in synovial fluids in canine RA, and this correlation was very strong $\frac{}{0}$ These findings indicate an association between immune complexes and rheumatoid factors in canine RA, suggesting that the complexes are, at least partially, formed by rheumatoid factors complexing with native IgG. Alternatively, rheuma $\overrightarrow{0}$ toid factor may be produced as a result of stimulation $\overrightarrow{-}$ by immune complexes, either articularly or within extra-articular lymphoid tissue. This rheumatoide factor could then bind to produce a larger, potentially? more inflammatory, immune complex. Hence inpo canine RA the role of rheumatoid factor in creating immune complexes is still tenable and would be ino agreement with the antiglobulin/immune complexo hypothesis of Zvaifler. ${ }^{24}$ The finding of lower levels? of rheumatoid factors in synovial fluids compared with sera, particularly in canine RA, might be explained by complexing and possibly clearance in the joint space and hence non-detection in our assays system. The ability of complexes to fix $\mathrm{Clq}$ iso indicative of a further pathological role by activationof the complement cascade, possibly leading 9000 inflammation. The $\mathrm{Clq}$ binding material found $\mathrm{in}$ the non-rheumatoid groups needs to be explained퀸다 may not necessarily be bound by immunoglobulinss nor result in $\mathrm{C} 3$ activation.

The relevance of rheumatoid factor in canineहै osteoarthritis is unclear but does not seem to be⿻ related to immune complex formation within the diseased joint. The sensitivity of the radioimmuno 3 assay may explain these findings and supports the contention that immune responses to altered IgG. may occur in osteoarthritis in man. ${ }^{25}$ Linear regres sion data suggest that although both rheumatoido. factors and immune complexes are present in the joints in osteoarthritis, they are unrelated events that is, they do not coincide in the same dog 0 Furthermore, rheumatoid factors are generally nok found within immune complexes in osteoarthritis. .9 The immune complexes found in osteoarthritis resulting from cruciate disease were also found by Niebauer and $\mathrm{Menzel}^{17}$ with a C1q binding assay. Im an attempt to define an antigen inducing immune complex formation these authors looked for evidences of autoimmunity to collagen (types I and II) in osteoarthritis. No link was found, but in a late study Niebauer et al showed serum and synoviab fluid antibodies, in cruciate disease, to collagen and II. $^{26} \mathrm{We}$ are now investigating the involvemen ${ }^{\circ}{ }^{?}$ of anticollagen antibodies and other antigen-antibody systems, which have been implicated in man, in canine RA. 
This work was supported by a project grant from the Wellcome Trust.

\section{References}

1 Bennett D. Inflammatory joint disease of the dog. Faculty of Veterinary Medicine. University of Glasgow, 1980. (PhD thesis.)

2 Bennett D. Immune-based non-erosive inflammatory joint disease of the dog. 3. Canine idiopathic polyarthritis. Journal of Small Animal Practise 1987; 28: 909-28.

3 Bennett D. Immune-based erosive inflammatory joint disease of the dog. Canine rheumatoid arthritis. 1. Clinical, radiological and laboratory investigations. Journal of Small Animal Practise 1987: 28: 779-97.

4 Bennett D. Immune-based erosive inflammatory joint disease of the dog. Canine rheumatoid arthritis. 2. Pathological investigations. Journal of Small Animal Practise 1987; 28: 799-819.

5 Newton C D. Lipowitz A J. Halliwell R E. Allen H L, Biery D N. Schumacher R. Rheumatoid arthritis in dogs. J Am Vet Med Assoc 1976: 168: 221-7.

6 Pedersen N C. Pool R R. Castles J J. Weisner K. Noninfectious canine arthritis: rheumatoid arthritis. J Am Vet Med Assoc 1976; 169: 295-303.

7 Elson C J, Carter S D, Cottrell B J, Scott D G I, Bacon P A Wallington T B. Complement activating properties of complexes containing rheumatoid factor in synovial fluids and sera from patients with rheumatoid arthritis. Clin Exp Immunol 1985; 59: 285-92.

8 Carter S D. Bourne J T. Elson C J, Hutton C W. Czudek R, Dieppe $\mathrm{P}$ A. Mononuclear phagocytes in rheumatoid arthritis: Fc-receptor expression by peripheral blood monocytes. Ann Rheum Dis 1984: 43: 424-9.

9 Wood D D. Hurwitz A I, Schultz R D. A latex test for canine rheumatoid factor. Vet Immunol Immunopathol 1980; 1 : 103-11.

10 Bennett D. Kirkham D. The laboratory identification of serum rheumatoid factor in the dog. J Comp Pathol 1987: 97: 541-50.

11 Terman D S. Moore D. Collin J, et al. Detection of immune complexes in sera of dogs with rheumatic and neoplastic diseases by ${ }^{125} \mathrm{I}-\mathrm{Clq}$ binding test. J Comp Pathol 1976; 89: 221-7.

12 Bennett D. Taylor D J. Bacterial infective arthritis in the dog Journal of Small Animal Practise 1987: 28: 207-30.
13 Bennett D, Kelly D F. Immune-based non-erosive inflammatory joint disease of the dog. 2. Canine polyarthritis/polymyositis complex. Journal of Small Animal Practise 1987; 28: 891-908.

14 Bennett D. Joint disease. In: Chandler E A, Sutton J B, Thompson D J, eds. Canine medicine and therapeutics. 2nd ed. Oxford: Blackwell Scientific, 1984: 166-205.

15 Bennett D, Duff S R I, Kene R O, Lee R. Osteochondritis dessicans and fragmentation of the coronoid process in the elbow joint of the dog. Vet Rec i 981; 109: 329-36.

16 Bennett D, Tennant B, Baughan J, May C, Lewis D G, Carter S D. Cruciate disease of the dog. A reappraisal. Journal of Small Animal Practise 1987; 29: 275-97.

17 Niebauer G W, Menzel E J. Immunological changes in canine cruciate ligament rupture. Res Vet Sci 1982; 32: 235-41.

18 Fraker P J, Speck J C. Protein and cell membrane iodinations with a sparingly soluble chloroamide $1,3,4,6$-tetrachloro-3a,6adiphenylglycoluril. Biochem Biophys Res Commun 1978; 80: 849-57.

19 Carter S D, Leslie R G Q. Reeves W G. Human monocyte binding of homologous monomer and complexed IgG. Immunology 1982; 46: 793-800.

20 Laemmli U K. Cleavage of structural proteins during the assembly of the head of the bacteriophage T4. Nature 1970; 227: 680-5.

21 Carter S D, Brennan F M, Grace S A, Elson C J. Clearance and organ localisation of particles and soluble complexes in mice with circulating complexes. Immunology 1984; 52: 761-9.

22 Mancini G, Carbonara A O, Heremans J F. Immunochemical quantitation of antigens by single radial immunodiffusion. Immunochemistry 1965: 2: 235-54.

23 Gioud-Paquet M, Auvinet M, Raffin T. et al. IgM rheumatoid factor (RF), IgA RF, IgE RF, and IgG RF detected by ELISA in rheumatoid arthritis. Ann Rheum Dis 1987; 46: 65-71.

24 Zvaifler $\mathrm{N} \mathrm{J}$. The immunopathology of joint inflammation in rheumatoid arthritis. Adv Immunol 1973; 16: 265-336.

25 Carter S D. Makh S R. Ponsford F M. Elson C J. Rheumatoid factor has increased reactivity with IgG from synovial fluids of patients with rheumatoid arthritis and osteoarthritis. $\mathrm{Br} J$ Rheumatol 1989; 28: 233-8.

26 Niebauer G W. Wolf B. Bashey R I. Newton C D. Antibodies to canine collagen type I and II in dogs with spontaneous cruciate ligament rupturc and osteoarthritis. Arthritis Rheum 1987: 30: 319-27. 